\title{
Incidence and Risk Factors of Non-Alcoholic Fatty Liver Disease among Non-Obese Patients Attending at Department of Gastroenterology, BSMMU
}

\author{
PRODIP KUMAR BISWAS, ${ }^{1}$ AKM HUMAYON KABIR, ${ }^{1}$ MOHAMMAD ENAMUL KARI M, ${ }^{2}$ \\ MOHAMMED SHAHADAT HOSSAI N, ${ }^{3}$ SUVASH CHANDRA VHADURY, ${ }^{4}$ MI R MASUDUR RHAMAN, ${ }^{5}$ \\ HASAN MASUD, ${ }^{6}$ MASUDUR RAHMAN KHAN ${ }^{7}$
}

\begin{abstract}
:
Introduction: Non-alcoholic fatty liver disease (NAFLD) is a distinct clinicopathologic entity characterized histologically by a spectrum ranging from simple steatosis to steatohepatitis (NASH), cirrhosis and even hepatocellular carcinoma (HCC).

Objective: To determine the incidenceand identify the risk factors of NAFLD in non-obese patients.

Methods: It was a cross sectional study done in Department of gastroenterology, Nuclear Medicine and ultrasound, Radiology and Imaging, Virology, Biochemistry, BSMMU, Dhaka from March 2012 to June 20I4. The patients more or equal to 18 years, non-obese were included. In this study total 190 patients were enrolled.

Results: Among them 38 patients were with fatty liver and 152 patients without fatty liver on the basis of ultrasonogram. Where 14I were male and 49 were female with mean age was $49.24+9.05$ years. Among total, 18.9\% had diabetes mellitus, $28.4 \%$ had dislipidaemia $24.4 \%$ had history of hypertension. Total $18.9 \%$ patients having history of diabetes mellitus, normal vs fatty liver disease $(20 \%$ vs $42.1 \%, p<0.00 I)$ and history of dyslipidemia $(10.5 \%$ vs $100 \%, p<0.001)$, Haemoglobin percentage was $12.16+1.32 \mathrm{gm} / \mathrm{dL}$, urine routine microscopic examination glucose present in $9.5 \%$ patients. SGPT 56.34 + 16.09 IU/L, SGOT 41.62 + 5.94 IU/L, alkaline phosphatase $99.31+$ 19.76 IU/L. We found 6.3\% patients were HBsAg positive and no patient was Anti HCV positive.

Conclusion: Sedentary life style, Metabolic syndrome, DM, dyslipidameia, are risk factors of NAFLD in non obese person. Elevated liver enzymes are consequences of NAFLD. Though this study has some limitations, it will give some information about emerging liver disease without viral hepatitis.
\end{abstract}

Key words: Non-alcoholic fatty liver disease, Dyslipidemia, Diabetes mellitus, Steatohepatitis

\section{Introduction:}

Non-alcoholic fatty liver disease (NAFLD) is highly prevalent in Western countries. ${ }^{1-3}$ It is often linked to obesity and the presence of metabolic syndrome (MS). NAFLD is a distinct clinicopatho-logic entity characterized histologically by a spectrum ranging from simple steatosis to steatohepatitis (NASH), cirrhosis and even hepatocellular carcinoma (HCC). ${ }^{1.4 .5}$

With the introduction of westernized lifestyle and the increasing frequencies of obesity in the Asia-Pacific region,

1. Assistant Professor, Medicine, Dhaka Medical College, Dhaka.

2. Assistant Professor, Gastroenterology, Shaheed Suhrawardy Medical College, Dhaka.

3. Assistant Professor, Medicine, Faridpur Medical College

4. Assistant Professor, Medicine, Sheikh Sayera Khatun Medical College, Gopalganj.

5. Lecturer, Community Medicine, Ibrahim Medical and BIRDEM Hospital, Dhaka.

6. Professor, Gastroenterology, BSMMU.

7. Associate Professor, Gastroenterology, BSMMU.

Correspondence: Dr. Prodip Kumar Biswas, Assistant Professor of Medicine, Dhaka Medical College Dhaka. Mobile: 01816828895, E-mail: prodiporka@yahoo.com the prevalence of NAFLD has increased over the past two decades. ${ }^{6-9}$ NAFLD has widely been considered a manifestation of metabolic syndrome in close relation to obesity $^{10-11}$.

\section{Materials and Methods:}

It was a cross sectional study done in Department of gastroenterology, Nuclear Medicine and ultrasound, Radiology and Imaging, Virology, Biochemistry BSMMU, Dhaka from March 2012 to June 2014. Patients attending in inpatient and outpatient department of Gastroenterology, BSMMU were enrolled for the study. The patients were more or equal to 18 years, non-obese [BMI (Body mass index) < 25 ] and gave consent for participating the study procedure. But the patients who were obese and consumed any amount of alcohol were not included. Subjects with the above criteria were sent for investigations for determination of risk factors of NAFLD by using the data collection form. The research was approved by the Ethical Review Committee of BSMMU, Dhaka. Data from the study was analyzed using SPSS (version 20) program. 


\section{Results:}

Demographic characteristics

Table I

Demographic characteristics of 190 patients with or without fatty liver

\begin{tabular}{lccccr}
\hline & All, N=190 & Fatty liver & Without Fatty \\
N=38 & & Liver, N=152 \\
Variable & Mean \pm SD & & Mean \pm SD & Mean \pm SD & $P-$ value \\
\hline Address(N) & Rural/Urban & $89 / 101$ & $21 / 17$ & $68 / 84$ & 0.247 \\
Age(Year) & $49.24 \pm 9.05$ & & $44.18 \pm 9.05$ & $50.50 \pm 8.63$ & $<0.001^{*}$ \\
Sex & Male/Female & $141 / 49$ & $26 / 12$ & $115 / 37$ & 0.364 \\
Life style & Sedentary/Active & $42 / 148$ & $22 / 16$ & $20 / 132$ & $<0.001^{*}$ \\
\hline
\end{tabular}

In our study total 190 patients were enrolled. Among them 38 patients were with fatty liver and 152 patients without fatty liver on the basis of ultrasonogram.

\section{Medical history:}

\section{Table II}

Shows the comparisons in main clinical characteristics between normal and fatty liver disease.

\begin{tabular}{|c|c|c|c|c|c|}
\hline \multirow[b]{2}{*}{ Variable } & \multicolumn{2}{|c|}{ All $\mathrm{N}=190$} & \multirow{2}{*}{$\begin{array}{c}\text { Fatty liver } N=38 \\
\text { Mean } \pm \text { SD }\end{array}$} & \multicolumn{2}{|l|}{ Without Fatty } \\
\hline & & & & Mean \pm SD & $\mathrm{P}$ - value \\
\hline$\overline{\mathrm{DM}}$ & & $18.9 \%$ & $42.1 \%$ & $20 \%$ & $<0.001^{*}$ \\
\hline Dyslipidaemia & $28.4 \%$ & $100 \%$ & $10.5 \%$ & $<0.001 *$ & \\
\hline Hypertension & $24.4 \%$ & $26 \%$ & $23.7 \%$ & 0.736 & \\
\hline Smoking & $36 \%$ & $18.4 \%$ & $40.5 \%$ & $<0.011 *$ & \\
\hline Change of Wt. & $14.7 \%$ & $42 \%$ & $7.9 \%$ & $<0.001^{*}$ & \\
\hline
\end{tabular}

Among 190 patients, 18.9\% had diabetes mellitus. 28.4\% dyslipidemia, 24.4\% hypertension. Multiple factors differ significantly between these two groups. Total $18.9 \%$ patients having diabetes mellitus, normal vs fatty liver (20\% vs $42.1 \%$ ), and dyslipidemia $10.5 \%$ vs $100 \%$, weight change $7.9 \%$ vs $42 \%$.

\section{Anthropometric characteristics}

Table III

Anthropometric characteristics of fatty liver and without fatty liver patients.

\begin{tabular}{lcccc}
\hline & All, N=190 & Fatty liver, N=38 & $\begin{array}{c}\text { Without Fatty } \\
\text { Liver, N=152 } \\
\text { Mean } \pm \text { SD }\end{array}$ & $P$ - value \\
\hline Variable & Mean \pm SD & Mean \pm SD & $124.21 \pm 5.26$ & 0.143 \\
SBP & $125.37 \pm 5.69$ & $125.66 \pm 5.77$ & $81.95 \pm 3.77$ & 0.970 \\
DBP & $81.95 \pm 3.96$ & $81.97 \pm 4.02$ & $73.26 \pm 8.55$ & 0.051 \\
Waist circumference & $75.68 \pm 7.75$ & $76.29 \pm 7.44$ & $81.87 \pm 8.47$ & $0.023^{*}$ \\
Hip circumference & $84.71 \pm 8.23$ & $85.42 \pm 8.04$ & $1.57 \pm 0.97$ & 0.053 \\
Height & $1.60 \pm 0.06$ & $1.60 \pm 0.06$ & $53.13 \pm 7.34$ & 0.050 \\
Weight & $55.16 \pm 5.63$ & $55.67 \pm 5.02$ & & \\
\hline
\end{tabular}




\section{Laboratory characteristics}

Table IV

Laboratory characteristics in fatty liver and without fatty liver patients

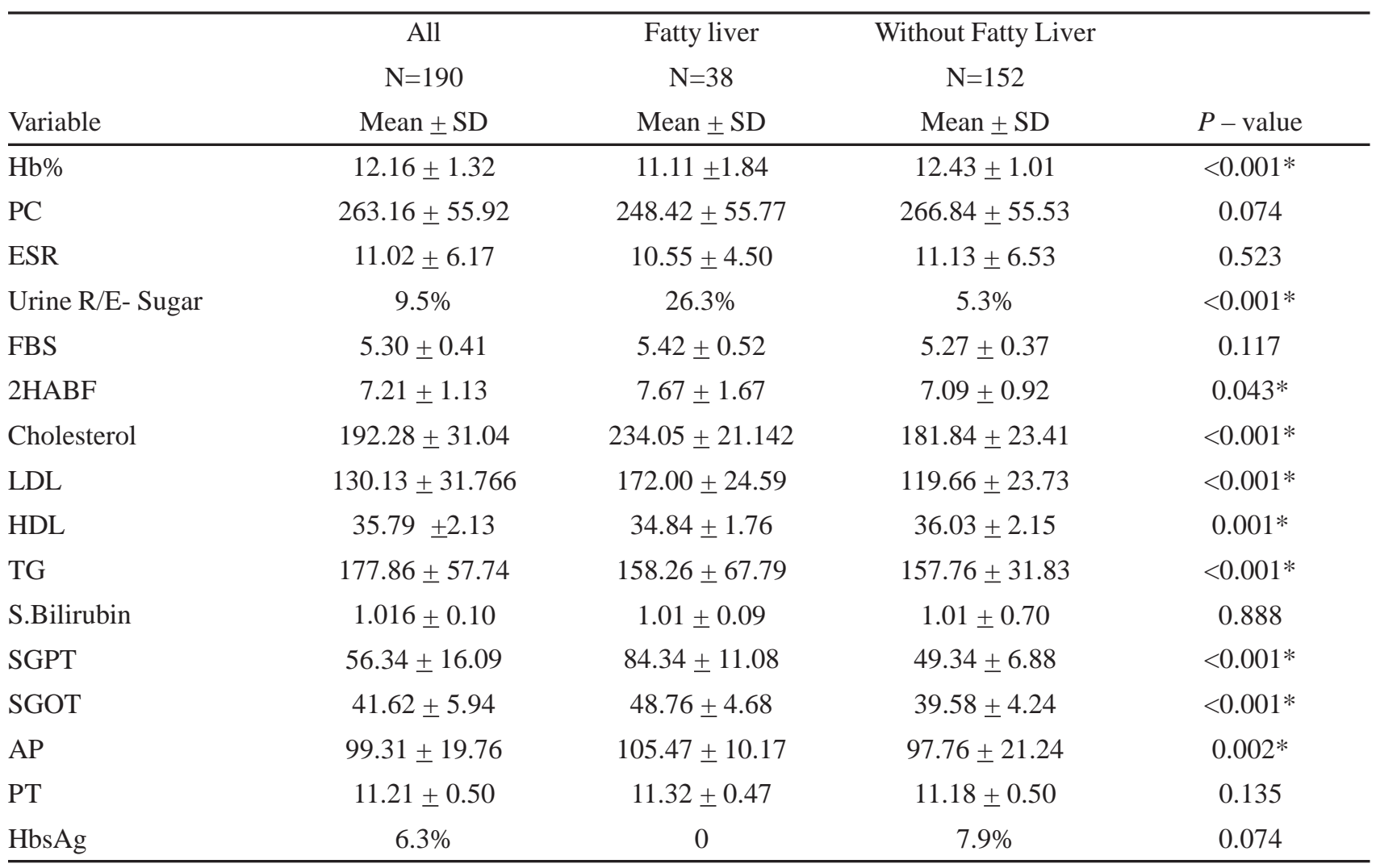

Table IV shows comparison of $\mathrm{Hb} \%$ to without fatty liver and fatty liver disease patients $(12.43 \pm 1.01$ vs $11.11 \pm 1.84$, $\mathrm{p}<0.001)$. Urine routine examination reveals presence of glucose in $26.3 \%$ ( $p<0.001$ ) fatty liver. Serum total cholesterol was significantly high in fatty liver patients, $181.84 \pm 23.41$ vs $234.05 \pm 21.14(p<0.001)$, Serum triglyceride significantly high in fatty liver patients 157.76 + 31.83 vs 158.26 +67.79 gm/dl ( $<<0.001)$, LDL cholesterol significantly high in fatty liver patients, $119.66 \pm 23.73$ vs $172 \pm 24.59$ ( $\mathrm{p}<0.001)$, HDL cholesterol significantly low in fatty liver patients $36.03 \pm 2.15$ vs $34.84 \pm 1.76 \mathrm{mg} / \mathrm{dl}$ (p $<0.001)$, SGPT was significantly high in fatty liver patients, $49.34 \pm 6.88$ vs $84.34 \pm 11.08$, SGOT was significantly high in fatty liver patients , $39.58 \pm 4.24$ vs $48.76 \pm 4.68 \mathrm{IU} /$ $\mathrm{L}(\mathrm{p}<0.001)$, Alkaline phosphates significantly more in fatty liver patients.

\section{Discussion}

This study showed that 38 (20\%) persons had NAFLD among 190 non obese patients attending the department of Gastroenterology, BSMMU. In India, there are several studies about NAFLD among nonobese person. It varied from $11 \%$ to $31.7^{12}$. But Margaritiet al ${ }^{13}$ in Greece found that NAFLD was about $12.5 \%$. Kim HJet al ${ }^{14}$ in Korea found that $23.4 \%$ had NAFLD in nonobese individual. In Bangladesh Alamet al. ${ }^{15}$ found that $25.6 \%$ patient had NAFLD among nonobese persons. The difference between this study and other studies may be due to some food habit, life style and ethnic background; and liver biopsy was not done in this study.

In this study, sedentary people had significant $(\mathrm{P}<0.001)$ NAFLD than active worker. Total $18.9 \%$ having history of diabetes mellitus, normal vs fatty liver disease $20 \%$ vs $42.1 \%$ ( $p<0.001$ ) and history of dyslipidemia $10.5 \%$ vs $100 \%$, $\mathrm{p}<0.001$, history of weight change $7.9 \%$ vs $42 \%$ ( $<<0.001$ ). In a population-based study by Kumar $\mathrm{R}$ et al ${ }^{16}$ from rural India, $52 \%$ of individuals with NAFLD were lean (BMI $<23)$. Interestingly, Das et al. ${ }^{12}$ also found that individuals with normal BMI had two-fold increases in risk for NAFLD than those with a $\mathrm{BMI}<18.5 \mathrm{Kg} / \mathrm{m}^{2}$. The prevalence of dyslipidemia and MS were significantly higher in lean NAFLD. BMI and abdominal obesity correlated with each 
other. A smaller Waist circumference was also reported in nonobese NAFLD previously. Visceral adipose tissues of lean NAFLD may be metabolically more active conferring metabolic risks leading to NAFLD. Both SGPT, SGO Tare statistically significant $(\mathrm{P}<0.001)$ in nonobese person. But other study in Bangladesh by Alam S et al. ${ }^{15}$ does not support the relation of SGPT and SGOT in case of non obese NAFLD patient. Serum total cholesterol, serum triglyceride, LDL cholesterol, HDL cholesterol were significantly changed in fatty liver. Serum profile level gives the similar result of Kumar R et al ${ }^{16}$ al but differs from the study of Alam S. et.al ${ }^{15}$

\section{Conclusion}

This is a small scale study based on the patients attending into tertiary centre, BSMMU. Non-alcoholic fatty liver disease (NAFLD) is a metabolic disorder originally assumed to be largely confined to residents of affluent, industrialized Western countries.In particular, there has been an upsurge in obesity-related metabolic syndrome in Asia-Pacific region. In this study, 20\% patients had NAFLD on ultrasound finding which is very similar to the study of India, Southeast Asia and even in some western countries. Sedentary life style, Metabolic syndrome, DM, dyslipidameia, are risk factors of NAFLD in non obese person. Elevated liver enzymes are consequences of NAFLD. Though this study has some limitations, it will give some information about emerging liver disease without viral hepatitis. As NAFLD number in nonobese person is increasing day by day, further study may be conducted to explore more information.

\section{Conflict of Interest: None}

\section{References}

1. Farrell GC, Larter CZ. Nonalcoholic fatty liver disease: from steatosis to cirrhosis. Hepatology. 2006;43:99-112.

2. Browning JD, SzczepaniakLS, Dobbins R et al. Prevalence of hepatic steatosis in an urban population in the United States: impact of ethnicity. Hepatology. 2004;40:1387-95.

3. Vernon G, Baranova A, Younossi ZM. Systematic review: the epidemiology and natural history of non-alcoholic fatty liver disease and non-alcoholic steatohepatitis in adults. Aliment. Pharmacol.Ther. 2011;34:274-85.

4. TeliMR, James OF, Burt AD, Bennett MK, Day CP. The natural history of nonalcoholic fatty liver: a follow-up study. Hepatology 1995;22:1714-19.
5. Bugianesi E, Leone N, Vanni E et al. Expanding the natural history of nonalcoholic steatohepatitis: from cryptogenic cirrhosis to hepatocellular carcinoma. Gastroenterology. 2002;123:134-40.

6. Farrell GC. NASH: what is it, and why is it important in the Asia-Pacific region? J. Gastroenterol. Hepatol. 2003;18: 124-38.

7. Chitturi S, Wong VW, Farrell G. Nonalcoholic fatty liver in Asia: firmly entrenched and rapidly gaining ground. J. Gastroenterol. Hepatol. 2011;26(Suppl. 1):163-72.

8. Farrell GC, Chitturi S, Lau GKK, Sollano J, the Asia-Pacific Working Party on NAFLD. Guidelines for the assessment andmanagement of non-alcoholic fatty liver disease in the Asia-Pacificregion. Executive summary. J. Gastroenterol. Hepatol. 2007;22:775-7.

9. Okanoue T, Umemura A, Yasui K et al. Nonalcoholic fatty liver disease and nonalcoholic steatohepatitis in Japan. J. Gastroenterol.Hepatol. 2011;26(Suppl. 1):153-62.

10. Chitturi S, Farrell GC, Hashimoto E et al. Non-alcoholic fatty liver disease in the Asia-Pacific region: definitions and overview of proposed guidelines. J. Gastroenterol. Hepatol. 2007;22:778-87.

11. Fabbrini E, Sullivan S, Klein S. Obesity and nonalcoholic fatty liver disease: biochemical, metabolic, and clinical implications. Hepatology. 2010;51:679-689.

12. Das K, Das K, Mukherjee PS, et al. Nonobese population in a developing country has a high prevalence of nonalcoholic fatty liver and significant liver disease. Hepatology 2010; 51:1593-1602.

13. Margariti E, Deutsch M, Manolakopoulos S, et al. Nonalcoholic fatty liver disease may develop in individuals with normal body mass index. Ann Gastroenterol 2012.

14. Kim HJ, Kim HJ, Lee KE et al. Metabolic significance of nonalcoholic fatty liver disease in nonobese, nondiabetic adults. Arch. Intern. Med. 2004;164:2169-75.

15. Alam S, Gupta UD, Alam M, Kabir J, Chowdhury ZR, Alam AK. Clinical, anthropometric, biochemical and histological characteristics of nonobese nonalcoholic fatty liver disease patients of Bangladesh. Indian J Gastroenterol. 2014; 33(5):452-7.

16. Kumar R, Rastogi A, Sharma MK, Bhatia V, Garg H, Bihari C, Sarin SK.Clinicopathological characteristics and metabolic profiles of non-alcoholic fatty liver disease in Indian patients with normal body mass index: Do they differ from obese or overweight non-alcoholic fatty liver disease? Indian J EndocrinolMetab. 2013;17(4):665-71. 